\section{Ape and hominid limb length}

SIR - The new discoveries of Australopithecus at Maka in Ethiopia ${ }^{1}$ are important additions to the fossil record of early hominid evolution. Among these finds, an incomplete, "very robust" humerus "from a large, presumably adult male" (MAKVP-1/3) figures prominently in inferences about locomotor capabilities of $A$. afarensis ${ }^{1,2}$. White et al. conclude that this

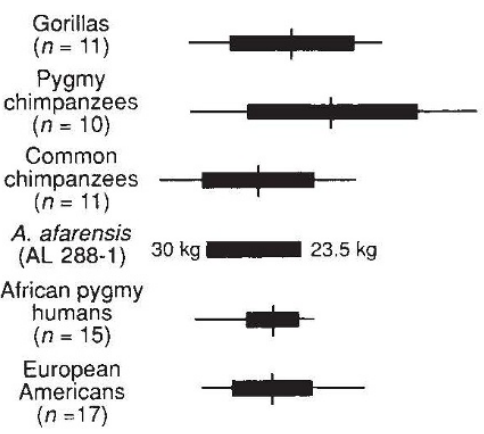

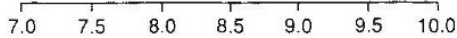

Humerus length $(\mathrm{mm}) /$ cube root of body mass $(\mathrm{g})$

Relative humerus length in African apes, modern humans and $A$. afarensis. The mean is represented by the vertical line; $\pm 1 \mathrm{~s}$.d. is indicated (solid bars) along with minimum and maximum values.

basal hominid "retained a powerful upper limb, but an upper limb that lacked the key arboreal adaptation of great length"1. Gee in News and Views ${ }^{2}$ suggests this means that the humerus of $A$. afarensis is "relatively short" and "not what one would expect of a tree-living creature".

The functional significance of relative limb lengths in $A$. afarensis has been debated for over a decade ${ }^{3-6}$. The key word here is relative; absolute lengths are unrelated to locomotor performance (for example, the highly suspensory gibbon has absolutely shorter humeri than do humans or gorillas). I pointed out ${ }^{3,5}$ that the relative humerus length of $A$. afarensis is similar to modern humans, and that "Lucy" (AL 288-1) cannot be distinguished from pygmy chimpanzees or pygmy humans in this regard. I have combined these data with new observations (see figure) to reassess the relationship between relative humerus length and locomotor repertoires in $A$. afarensis, modern humans and African apes. All species overlap extensively in relative humerus length, with pygmy chimpanzees possessing the longest, on average, and common chimpanzees the shortest. A Kruskal-Wallis test of the five extant samples indicates that there are no significant differences in this index $(P>0.12)$. Model II log-log regression of humerus length on mass confirms this result; the scaling relationship is best described as isometric (for the sample as a whole and for African apes alone). Put simply, arm length relative to body size cannot discriminate by itself among species that are adept arborealists (pygmy and common chimpanzees), primarily terrestrial but capable climbers (gorillas) and habitually terrestrial bipeds (humans).

In my view, the conclusions reached by White et al. ${ }^{1}$ and $\mathrm{Gee}^{2}$ are not supported. The relative length of the humerus in $A$. afarensis might be precisely the length one would expect of a species at home both on the ground and in the trees. Other aspects of the postcranial skeleton that reflect or facilitate arboreal behaviours are consistent with this interpretation ${ }^{7,8}$. It is also indisputable that $A$. afarensis exhibits skeletal traits linked to terrestrial bipedalism, but terrestriality does not necessarily preclude arboreality.

William L. Jungers

Department of Anatomical Sciences,

School of Medicine,

State University of New York,

Stony Brook, New York 11794-8081, USA

WHITE REPLIES - Jungers speculates that $A$. afarensis was "at home both on the ground and in the trees" because a ratio of humeral length to body mass does not discriminate among African apes, humans and $A$. afarensis. Such a test might be appropriate if these taxa did not differ in other crucially important locomotor characters. However, they do differ dramatically.

First, Jungers has elsewhere argued that humeral length is negatively allometric with increasing body mass ${ }^{3,9}$. He now concludes that it is isometric. Which is correct?

Second, why has Jungers excluded hylobatids and orangutans from his sample? Elsewhere he has described these arboreally adapted hominoids as having "pronounced relative forelimb elongation" (emphasis added).

Third, the African apes are knucklewalking terrestrial quadrupeds and some-

\footnotetext{
White. T. D. et al. Nature 366 . 261-265 (1993)

3. Gee, H. Nature 366, 207 (1993).

4. Jungers, W. L. Nature 297, 676-678(1982).

5. Jungers, W. L. in Origine(s) de la Bipedie chez les Hominides (eds Coppens, Y. \& Senut, B.) 215-224 (Editions du CNRS, Paris, 1991).

6. Latimer, B. in Origine(s) de la Bipedie chez les Hominides (eds Coppens, Y. \& Senut, B.) 169-176 (Editions du CNRS, Paris, 1991)

7. Susman, R. L., Stern, J.T. Jr \& Jungers, W. L. Folia primatol. 43, 113-156 (1984).

8. Hunt, K. J. hum. Evol. 26, 183-202 (1994).

9. Jungers, W. L. in Size and Scaling in Primate Biology (ed Jungers, W.) 345-381 (Plenum. New York, 1985)

10. Doran, D. M. Am. J. phys. Anthrop. 91. 99-115 (1993).

11. Latimer, B. \& Lovejoy, C. O. Am J. phys. Anthrop. 78 369-386: 82, 125-134:83,13-23(1989-90).

2. Lovejoy, C. O. Sci. Am. 256, 11:118-125 (1988)

13. Latimer, B., Ohman, J. C. \& Lovejoy, C. O. Am. J. phys. Anthrop. 74. 155-175(1987)

14. Johanson. D. C. et al. Am. J. phys. Anthrop. 57, 373-724 (1982)

15. White, T D. \& Suwa, G. Am J. phys. Anthrop 73 $485-515(1987)$
}

times arboreal feeders (Pan troglodytes averages 84 per cent of total locomotor activities on the ground $\left.{ }^{10}\right)$. Chimpanzees are agile arborealists largely because they rely on flexible, grasping hindlimbs with opposable great toes. The hindlimb of $A$. afarensis was extensively specialized for bipedality, with loss of virtually all grasping ability. Would it not exhibit morphology consistent with other hominoids whose forelimbs are also uncoupled from knuckle-walking if it were "at home in the trees?" MAK-VP-1/3 is an ideal test of this locomotor hypothesis. As noted by Gee, it lacks any such morphology. It is both retroflexed (like only humans among hominoids) and short by any arboreal (not knuckle-walking) standard.

Since leopards, lizards, snakes, baboons and modern humans can all climb trees, we agree with Jungers that "terrestriality does not necessarily preclude arboreality". At issue, however, is how to warrant our inferences about Pliocene hominid activities. The total morphological pattern of the $A$. afarensis locomotor skeleton includes the relatively shortest manual (and pedal) phalanges of any primate except Homo sapiens; a completely transformed hip abductor apparatus; full lumbosacral lordosis; habitual full extension of the knee; a reorganized ankle joint with horizontal plafond; and a foot with adducted hallux and longitudinal and transverse arches ${ }^{6,11-15}$. As Gee points out, it seems inappropriate to suggest that a short, retroflexed, human-like humerus represents evidence for ape-like arboreality in such a species.

\section{Tim D. White}

Department of Anthropology,

University of California,

Berkeley, California 94720, USA

\section{1st century read}

SIR - For Guy Hewlett's comment ( $\mathrm{Na}$ ture 368,$697 ; 1994)$, that there is a $95 \%$ probability that we will be reading correspondence relating to Gott's over the next 30.6 years, to be credible in Gott's terms, one has to accept Gott's assumptions (the Copernican view). Those reading ihis Scientific Correspondence, as well as the original Hypothesis, now have a different Gott probability time period to contend with to that suggested by Hewlett.

Criticism so far of Gott's Hypothesis largely springs from the interpretation and recognition (or lack of) of his assumptions - a largely fruitless game we can all play. And so, in Machiavellian gratification of my human desire for notoriety, I have placed my travelling atomic alarm clock in a box marked 'Gott', set for AD 2024, with instructions to write to Nature.

\section{Jonathan Cowie}

5 Charlieville, Northumberland Heath, Kent DA8 1HJ, UK 